\title{
Research \\ Simultaneous multi-depth assessment of tissue oxygen saturation in thenar and forearm using near-infrared spectroscopy during a simple cardiovascular challenge
}

\author{
Rick Bezemer ${ }^{1,2}$, John M Karemaker ${ }^{3,4}$, Eva Klijn², Daniel Martin ${ }^{5}$, Kay Mitchell ${ }^{5}$, Mike Grocott ${ }^{5}$, \\ Michal Heger ${ }^{6}$ and Can Ince ${ }^{1,2}$
}

\begin{abstract}
1'Department of Translational Physiology, Academic Medical Center, University of Amsterdam, Meibergdreef 9, 1105 AZ Amsterdam, the Netherlands 2Department of Intensive Care, Erasmus MC, University Medical Center Rotterdam, 's-Gravendijkwal 230, 3015 CE Rotterdam, the Netherlands ${ }^{3}$ Department of Systems Physiology, Academic Medical Center, University of Amsterdam, Meibergdreef 9, 1105 AZ Amsterdam, the Netherlands ${ }^{4}$ Heart Failure Research Center, Academic Medical Center, University of Amsterdam, Meibergdreef 9, 1105 AZ Amsterdam, the Netherlands

${ }^{5}$ Centre for Altitude, Space, and Extreme Environment Medicine, University College London Institute of Human Health and Performance, Archway Campus, Highgate Hill, London N19 5LW, UK

${ }^{6}$ Department of Experimental Surgery, Academic Medical Center, University of Amsterdam, Meibergdreef 9, 1105 AZ Amsterdam, the Netherlands
\end{abstract}

Corresponding author: Rick Bezemer, r.bezemer@amc.uva.nl

Published: 30 November 2009

This article is online at http://ccforum.com/content/13/S5/S5

(c) 2009 BioMed Central Ltd
Critical Care 2009, 13(Suppl 5):S5 (doi:10.1186/cc8003)

\section{Introduction}

Hypovolemia and hypovolemic shock are life-threatening conditions that occur in numerous clinical scenarios such as in the emergency room, during surgery, and in intensive care patients [1-4]. Compensatory mechanisms that protect against alterations in blood pressure make standard hemodynamic measurements poor indicators for early assessment of hypovolemia and shock. One of these compensatory mechanisms is extreme peripheral vasoconstriction, and therefore measurement of alterations in the peripheral circulation could aid in the early detection of hypovolemia.

To this end, near-infrared spectroscopy (NIRS) - an optical technique for measuring tissue oxygen saturation - has been widely explored, successfully and unsuccessfully, in attempts to identify the severity of hypovolemia [5-8], to monitor blood loss [9-11] and guide resuscitation [12-14], and to predict patient outcome [15-17]. The main problem with the interpretation of tissue oxygen saturation $\left(\mathrm{StO}_{2}\right)$ data from these studies, however, is the diversity of methodologies used for assessing $\mathrm{StO}_{2}$. Two major aspects regarding the inconsistent methodology are the application site and the probing depth. The application site is important because differences may exist in the sensitivity of underlying muscle groups and other anatomical structures to cardiovascular challenges such as central hypovolemia. The probing depth, additionally, determines the relative contribution of muscular and (sub)dermal tissue to the $\mathrm{StO}_{2}$ measurement.

ANOVA $=$ analysis of variance; LBNP = lower body negative pressure; NIRS = near-infrared spectroscopy $\mathrm{StO}_{2}=$ tissue oxygen saturation 
Although it is often discussed that these aspects affect the assessment of $\mathrm{StO}_{2}$, no studies have simultaneously measured $\mathrm{StO}_{2}$ in the thenar and forearm at multiple depths. In order to investigate the actual measurement site dependence and probe dependence of NIRS in response to hemodynamic changes, such as hypovolemia, we applied a simple cardiovascular challenge: a posture change from supine to upright, causing a decrease in stroke volume (as in hypovolemia) and a heart rate increase in combination with peripheral vasoconstriction to maintain adequate blood pressure [18-22]. Multi-depth NIRS was used to assess changes in $\mathrm{StO}_{2}$ in the thenar and forearm in response to the hemodynamic changes associated with the described cardiovascular challenge.

\section{Materials and methods Subjects}

The study protocol was approved by the Medical Ethics Committee of University College London. Nine healthy, normotensive volunteers who were not receiving any vasoactive medication were requested to refrain from consuming caffeine-containing beverages prior to the measurements. The room temperature was maintained at $20 \pm 1^{\circ} \mathrm{C}$.

\section{Hemodynamic monitoring}

Prior to the experimental protocol, systolic and diastolic blood pressures were measured in the supine position using an automatic blood pressure cuff around the upper arm (type M5-I, Omron Matsusaka Co. Ltd, Japan). The heart rate was continuously monitored during the entire experimental protocol, using a fingertip pulse oximeter (Defibron, Groningen, the Netherlands).

\section{Near-infrared spectroscopy}

$\mathrm{StO}_{2}$ was non-invasively and simultaneously measured in the thenar and forearm by applying one multi-depth NIRS probe on the skin of the thenar eminence and one multi-depth NIRS probe on the lateral side of the anterior surface of the forearm brachioradialis muscle, both placed in parallel to the orientation of the respective target muscle groups (Hutchinson Technology, Hutchinson, MN, USA). The NIRS devices employ reflectance mode probes that have one $1.5 \mathrm{~mm}$ optical fiber to illuminate the tissue and two optical fibers to detect the backscattered light from the tissue. The spatial separation between the illumination fiber and the two detection fibers is $15 \mathrm{~mm}$ and $25 \mathrm{~mm}$, respectively. As described by Cui and colleagues, the NIRS measurement depth increases with increasing distance between the illuminating and detecting fibers [23]. The $25 \mathrm{~mm}$ separated fiber therefore measures a greater and deeper tissue volume than the $15 \mathrm{~mm}$ separated fiber. By subtracting the spectral absorbance measured by the $15 \mathrm{~mm}$ fiber from that measured by the $25 \mathrm{~mm}$ fiber, similar to the NIRS device used by the group of Torella and colleagues $[9,10]$, the spectral absorbance between these two probing depths was determined and used to calculate $\mathrm{StO}_{2}$ in this isolated layer of tissue.
The relative optical attenuation of the backscattered light at four wavelengths $(680 \mathrm{~nm}, 720 \mathrm{~nm}, 760 \mathrm{~nm}$, and $800 \mathrm{~nm}$ ) was measured for each probing depth to calculate two second-derivative attenuation values, one centered at $720 \mathrm{~nm}$ and the other at $760 \mathrm{~nm}$ [24]. A ratio of the $720 \mathrm{~nm}$ to $760 \mathrm{~nm}$ second-derivative values is directly related to $\mathrm{StO}_{2}$, defined as $\left[\mathrm{HbO}_{2}\right] /\left([\mathrm{Hb}]+\left[\mathrm{HbO}_{2}\right]\right)$, via a calibration table that is permanently stored within the device [25].

\section{Experimental protocol}

Subjects started the experiment in a supine position. After stable baseline traces were obtained for the heart rate and NIRS measurements, the subjects changed posture to an upright position. Fifteen minutes later, the subjects changed posture back to supine. The heart rate and $\mathrm{StO}_{2}$ data were obtained during the supine position, then upright for 5 and 15 minutes, and again in the supine position. The hand and forearm were kept at heart level during the entire experimental protocol using a sling.

\section{Statistical analysis}

Statistical analysis was performed in GraphPad Prism software (GraphPad Software, San Diego, CA, USA). Normal distribution of the data was confirmed for each $\mathrm{StO}_{2}$ parameter $(15 \mathrm{~mm}, 25 \mathrm{~mm}$, and $25-15 \mathrm{~mm})$ using the D'Agostino and Pearson omnibus normality test. Comparative analysis between groups was performed using analysis of variance (ANOVA) with a Bonferroni post-hoc test. All data are presented as the mean \pm standard deviation. Differences between groups with $P<0.05$ were considered statistically significant.

\section{Results}

\section{Subject demographics}

The subject population consisted of six females and three males (all Caucasian) with a mean \pm standard deviation age of $39 \pm 14$ years, height of $171 \pm 6 \mathrm{~cm}$, and weight of $70 \pm 8 \mathrm{~kg}$. Systolic and diastolic blood pressures were $110 \pm 8$ and $69 \pm 7 \mathrm{mmHg}$, respectively.

\section{Heart rate and $\mathrm{StO}_{2}$}

No differences in heart rate and $\mathrm{StO}_{2}$ values between the first and second supine time points (beginning and the end of the experimental protocol, respectively) and between the first and second upright time points (after 5 and 15 minutes upright, respectively) were observed. The data were therefore categorized into supine and upright.

Repeated-measures ANOVA showed that a posture change from supine to upright resulted in a significant increase in heart rate (Figure 1). Furthermore, thenar $\mathrm{StO}_{2}$ did not respond to the hemodynamic changes following the posture change (Figure 2, left), whereas forearm $\mathrm{StO}_{2}$ did (Figure 2, right). In the forearm, $\mathrm{StO}_{2}$ was significantly lower $(P<0.001)$ in the upright position with respect to the supine position. $\mathrm{StO}_{2}$ measured in the supine position was significantly higher 
Figure 1

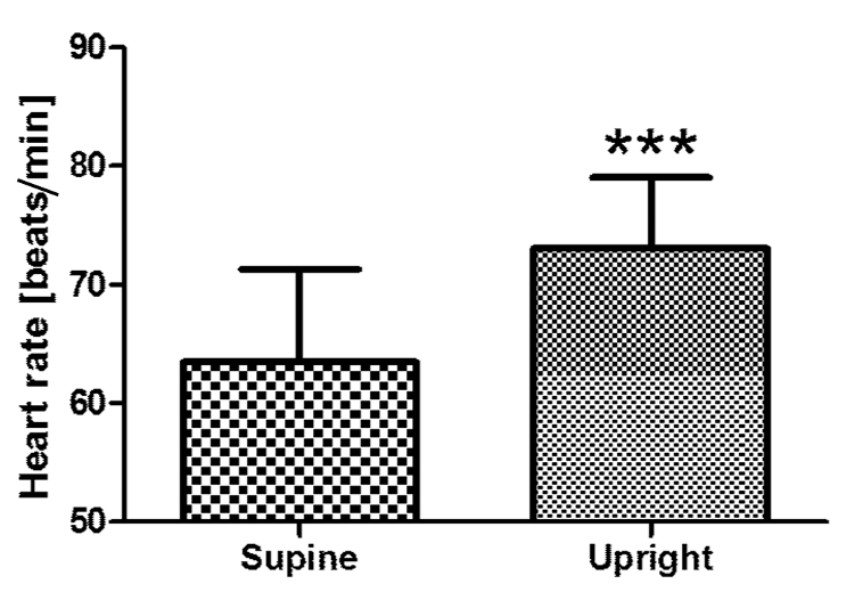

Heart rate in the supine and upright positions. ${ }^{\star \star \star} P<0.001$ for upright versus supine position.

in the thenar than in the forearm $(P<0.05$ for the $15 \mathrm{~mm}$ and $25 \mathrm{~mm}$ probing depths and $P<0.001$ for the $25-15 \mathrm{~mm}$ probing depth). In the forearm, the mean \pm standard deviation change in $\mathrm{StO}_{2}$ was $7.1 \pm 4.0$ for $15 \mathrm{~mm}, 8.6 \pm 4.5$ for $25 \mathrm{~mm}$, and $10.9 \pm 6.0$ for $25-15 \mathrm{~mm}$ probing depth, respectively.

Regular ANOVA (not repeated measures) revealed no significant differences between supine and upright positions for either the thenar or the forearm for all probing depths, indicating that the change in $\mathrm{StO}_{2}$ during the posture change from supine to upright (analyzed using repeated-measures ANOVA) is more important than the absolute $\mathrm{StO}_{2}$ values for monitoring the effects of hemodynamic changes on peripheral tissue oxygenation.

$\mathrm{StO}_{2}$ values in the thenar during both supine and upright positions were similar in females and males, but in the forearm $\mathrm{StO}_{2}$ values tended to be lower in females than in males (number too small for statistical analysis). The $\mathrm{StO}_{2}$ decrease caused by a posture change from supine to upright, however, was of a similar extent in females and males for both the thenar and the forearm for all probing depths.

\section{Discussion and conclusions}

The present study investigated the application site dependence and probing depth dependence of NIRS measurements for the detection of changes in $\mathrm{StO}_{2}$ following a simple cardiovascular challenge. The main findings were that forearm $\mathrm{StO}_{2}$ is a more sensitive parameter to hemodynamic changes than thenar $\mathrm{StO}_{2}$ and that the depth at which $\mathrm{StO}_{2}$ is measured is of minor influence. In addition, our data indicated that the change in $\mathrm{StO}_{2}$ during a cardiovascular challenge is more important than the absolute $\mathrm{StO}_{2}$ values for monitoring the effects of hemodynamic changes on peripheral tissue oxygenation.

In the present study, a simple cardiovascular challenge was created by a posture change from supine to upright. This challenge is associated with a decrease in stroke volume, an increase in heart rate, and an increase in peripheral vascular tone in order to maintain adequate blood pressure. Since we did not measure the stroke volume and cardiac output we could not assess the extent of this cardiovascular challenge further than its effect on the heart rate. The observed increases in heart rate, however, indicate that the applied posture change did induce significant alterations at the

Figure 2
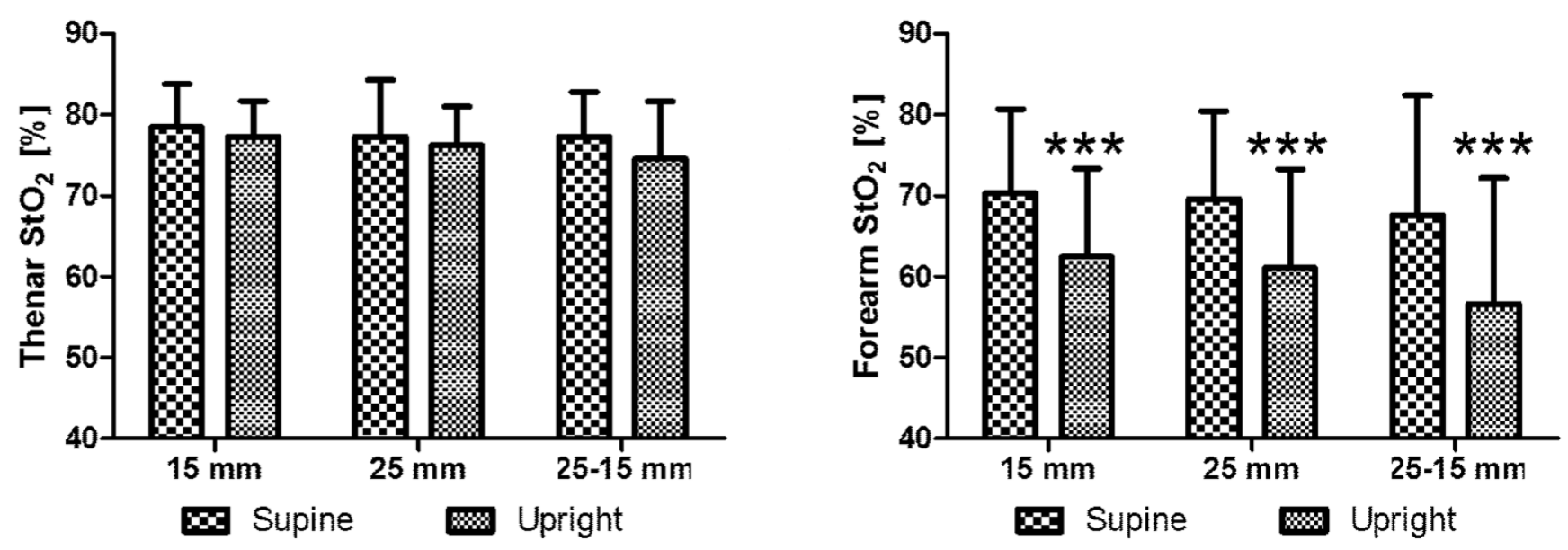

Thenar and forearm tissue oxygen saturation using different probe spacings. Thenar tissue oxygen saturation $\left(\mathrm{StO}_{2}\right)$ (left), and forearm $\mathrm{StO}{ }_{2}(\mathrm{right})$ in the supine and upright positions as measured using different probe spacings. ${ }^{* \star *} P<0.001$ for upright versus supine position. 
macrocirculatory level. This is supported by several studies investigating hemodynamic responses in healthy subjects undergoing passive upright tilt [18-22]. Furthermore, the focus of the present study was to investigate the capability of NIRS to detect alterations in $\mathrm{StO}_{2}$ following macrocirculatory changes and, especially, the role of NIRS application site and probing depth. This capability we have evidently shown.

We have shown that forearm $\mathrm{StO}_{2}$ is more responsive to hemodynamic changes than thenar $\mathrm{StO}_{2}$. This is surprising given that the employed NIRS device is promoted for use on the thenar and not the forearm. Many researchers using NIRS technology claim that the contribution of (sub)dermal tissue to the NIRS signal is deleterious for its interpretation, and many optical and algorithmic solutions are explored to minimize this effect. Indeed, the present study shows that the standard deviation in distribution of $\mathrm{StO}_{2}$ values obtained in the forearm is much larger compared with that in the thenar and, in addition, $\mathrm{StO}_{2}$ values in the forearm tended to be lower in females than in males. Both these observations could be attributed to interindividual variability in the contribution of subdermal adipose tissue to the NIRS signal. The variance in forearm $\mathrm{StO}_{2}$ appeared to be independent of probing depth, however, as the $15 \mathrm{~mm}, 25 \mathrm{~mm}$, and $25-15 \mathrm{~mm}$ signals all provided very similar $\mathrm{StO}_{2}$ values. Furthermore, the $\mathrm{StO}_{2}$ change in response to the posture change was of similar extent for all probing depths. Taken together, these results suggest that the (micro)vascular response to a cardiovascular challenge might be similar in (sub)dermal tissue and in the muscle, and it is the forearm tissue as a whole that is more sensitive to hemodynamic changes compared to the thenar.

In a recent study by Soller and colleagues, where central hypovolemia was induced by lower body negative pressure (LBNP) [6], forearm $\mathrm{StO}_{2}$ was measured using a device developed by the authors (equipped with a $30 \mathrm{~mm}$ probe) and was shown to be a sensitive parameter to the stroke volume decrease associated with application of LBNP. The stroke volume and forearm $\mathrm{StO}_{2}$ decreased immediately at onset of simulated hypovolemia (LBNP $=-15 \mathrm{mmHg}$ ), while the heart rate remained unresponsive until an LBNP of $-45 \mathrm{mmHg}$ and increased significantly at an LBNP of $-60 \mathrm{mmHg}$. These data support our finding that forearm $\mathrm{StO}_{2}$ is a sensitive measure to detect alterations in cardiovascular autonomic tone associated with central hypovolemia.

In a subsequent LBNP study by the same group [7], thenar $\mathrm{StO}_{2}$ was measured with a device similar to the device used in the present study (HT device, $15 \mathrm{~mm}$ probe) and forearm $\mathrm{StO}_{2}$ was measured using the device developed by the authors ( $30 \mathrm{~mm}$ probe). The authors found that their device on the forearm was more sensitive to hypovolemia than the HT device on the thenar, and concluded that their device had superior sensitivity to detect acute hypovolemia. The authors furthermore hypothesize that the $15 \mathrm{~mm}$ probe spacing of the
HT device is probably too small to collect light from a sufficiently deep layer of muscular tissue to detect hypovolemia and, additionally, it was suggested that the relatively large contribution of (sub)dermal tissue (due to the smaller probing depth) might affect the $\mathrm{StO}_{2}$ measurements. The present study, however, where thenar and forearm $\mathrm{StO}_{2}$ were measured at multiple depths simultaneously, clearly shows that forearm $\mathrm{StO}_{2}$ is a more sensitive parameter to detect changes in cardiovascular autonomic tone than thenar $\mathrm{StO}_{2}$ (both measured with the HT device), and that the sensitivity of these measurements was independent of probing depth.

Crookes and colleagues showed in a study in trauma patients that thenar $\mathrm{StO}_{2}$ could be used to identify severe hypovolemic shock, but that it was unable to detect mild and moderate hypovolemic shock [5]. The patient population in that study was categorized into mild, moderate, and severe hypovolemic shock, where maximum heart rates were $108 \pm 26$ beats/ minute, $118 \pm 23$ beats/minute, and $130 \pm 35$ beats/minute, respectively. Their finding that thenar $\mathrm{StO}_{2}$ is insensitive to mild and moderate hypovolemic shock is supported by our data and, in addition, our data support the use of forearm $\mathrm{StO}_{2}$ as a more sensitive parameter for the detection of central hypovolemia and hypovolemic shock in (trauma) patients.

In conclusion, the present study has shown that forearm $\mathrm{StO}_{2}$ is more responsive to hemodynamic changes compared with thenar $\mathrm{StO}_{2}$ and that the response is similar for the applied probing depths. In addition, our results indicate that the change in $\mathrm{StO}_{2}$ during a cardiovascular challenge is more important than the absolute $\mathrm{StO}_{2}$ values for monitoring the effects of hemodynamic changes on peripheral tissue oxygenation. Our data furthermore suggest that the (micro)vascular response to a cardiovascular challenge might be similar in (sub)dermal tissue and in the muscle, and that it is the forearm tissue as a whole that is more sensitive to hemodynamic changes compared to the thenar tissue. This hypothesis, however, warrants further investigation.

\section{Competing interests}

Multi-depth NIRS devices were provided by Hutchinson Technologies.

\section{Acknowledgements}

The present research is supported by the Landsteiner Foundation for Blood Transfusion Research.

This article is part of Critical Care Volume 13 Supplement 5: Tissue oxygenation $\left(\mathrm{StO}_{2}\right)$ in healthy volunteers and critically-ill patients. The full contents of the supplement are available online at http://ccforum. $\mathrm{com} /$ supplements/13/S5. Publication of the supplement has been supported with funding from Hutchinson Technology Inc.

\section{References}

1. Wo CC, Shoemaker WC, Appel PL, Bishop MH, Kram HB, Hardin E: Unreliability of blood pressure and heart rate to evaluate cardiac output in emergency resuscitation and critical illness. Crit Care Med 1993, 21:218-223. 
2. Orlinsky M, Shoemaker W, Reis ED, Kerstein MD: Current controversies in shock and resuscitation. Surg Clin North Am 2001, 81:1217-1262.

3. Porter JM, Ivatury RR: In search of the optimal end points of resuscitation in trauma patients: a review. J Trauma 1998, 44: 908-914.

4. Wilson M, Davis DP, Coimbra R: Diagnosis and monitoring of hemorrhagic shock during the initial resuscitation of multiple trauma patients: a review. J Emerg Med 2003, 24:413-422.

5. Crookes BA, Cohn SM, Bloch S, Amortegui J, Manning R, Li P, Proctor MS, Hallal A, Blackbourne LH, Benjamin R, Soffer D, Habib F, Schulman Cl, Duncan R, Proctor KG: Can near-infrared spectroscopy identify the severity of shock in trauma patients? J Trauma 2005, 58:806-813.

6. Soller BR, Yang Y, Soyemi OO, Ryan KL, Rickards CA, Walz JM, Heard SO, Convertino VA: Noninvasively determined muscle oxygen saturation is an early indicator of central hypovolemia in humans. J Appl Physio/ 2008, 104:475-481.

7. Soller BR, Ryan KL, Rickards CA, Cooke WH, Yang Y, Soyemi OO, Crookes BA, Heard SO, Convertino VA: Oxygen saturation determined from deep muscle, not thenar tissue, is an early indicator of central hypovolemia in humans. Crit Care Med 2008, 36:176-182.

8. Soller BR, Yang Y, Soyemi OO, Heard SO, Ryan KL, Rickards CA, Convertino VA, Cooke WH, Crookes BA: Near infrared spectroscopy. Crit Care Med 2009, 37:385.

9. Torella F, Cowley RD, Thorniley MS, McCollum CN: Regional tissue oxygenation during hemorrhage: can near infrared spectroscopy be used to monitor blood loss? Shock 2002, 18: 440-444.

10. Torella F, Haynes SL, McCollum CN: Cerebral and peripheral near-infrared spectroscopy: an alternative transfusion trigger? Vox Sang 2002, 83:254-257.

11. Beilman GJ, Groehler KE, Lazaron V, Ortner JP: Near-infrared spectroscopy measurement of regional tissue oxyhemoglobin saturation during hemorrhagic shock. Shock 1999, 12:196200.

12. Crookes BA, Cohn SM, Burton EA, Nelson J, Proctor KG: Noninvasive muscle oxygenation to guide fluid resuscitation after traumatic shock. Surgery 2004, 135:662-670.

13. Cohn SM, Crookes BA, Proctor KG: Near-infrared spectroscopy in resuscitation. J Trauma 2003, 54(5 Suppl):S199-S202.

14. McKinley BA, Marvin RG, Cocanour CS, Moore FA: Tissue hemoglobin $\mathrm{O}_{2}$ saturation during resuscitation of traumatic shock monitored using near infrared spectrometry. J Trauma 2000, 48:637-642.

15. Ikossi DG, Knudson MM, Morabito DJ, Cohen MJ, Wan JJ, Khaw L, Stewart CJ, Hemphill C, Manley GT: Continuous muscle tissue oxygenation in critically injured patients: a prospective observational study. J Trauma 2006, 61:780-788.

16. Moore FA, Nelson T, McKinley BA, Moore EE, Nathens AB, Rhee $\mathrm{P}$, Puyana JC, Beilman GJ, Cohn SM, $\mathrm{StO}_{2}$ Study Group: Massive transfusion in trauma patients: tissue hemoglobin oxygen saturation predicts poor outcome. J Trauma 2008, 64: 1010-1023.

17. Cohn SM, Nathens AB, Moore FA, Rhee P, Puyana JC, Moore EE, Beilman GJ, $\mathrm{StO}_{2}$ in Trauma Patients Trial Investigators: Tissue oxygen saturation predicts the development of organ dysfunction during traumatic shock resuscitation. J Trauma 2007, 62:44-54.

18. Sprangers RL, Veerman DP, Karemaker JM, Wieling W: Initial circulatory responses to changes in posture: influence of the angle and speed of tilt. Clin Physiol 1991, 11:211-220.

19. Chan GS, Middleton PM, Celler BG, Wang L, Lovell NH: Change in pulse transit time and pre-ejection period during upright tilt-induced progressive central hypovolaemia. J Clin Monit Comput 2007, 21:283-293.

20. Zaidi A, Benitez D, Gaydecki PA, Vohra A, Fitzpatrick AP: Haemodynamic effects of increasing angle of head up tilt. Heart 2000, 83:181-184.

21. Wieling W, Van Lieshout JJ, Ten Harkel AD: Dynamics of circulatory adjustments to upright tilt and tilt-back in healthy and sympathetically denervated subjects. Clin Sci (Lond) 1998, 94:347-352.

22. Smith JJ, Porth CM, Erickson M: Hemodynamic response to the upright posture. J Clin Pharmacol 1994, 34:375-386.

23. Cui W, Kumar C, Chance B: Experimental study of migration depth for the photons measured at sample surface. Proc SPIE 1991, 1431:180-191.

24. Myers DE, Cooper CE, Beilman GJ, Mowlem JD, Anderson LD, Seifert RP, Ortner JP: A wide gap second derivative NIR spectroscopic method for measuring tissue hemoglobin oxygen saturation. Adv Exp Med Biol 2006, 578:217-222.

25. Myers DE, Anderson LD, Seifert RP, Ortner JP, Cooper CE, Beilman GJ, Mowlem JD: Noninvasive method for measuring local hemoglobin oxygen saturation in tissue using wide gap second derivative near-infrared spectroscopy. J Biomed Opt 2005, 10:034017. 